\title{
MASTER
}

\section{ASTHMA AND AIR POLLUTION IN THE LOS ANGELES AREA}

ALICE S. WHITTEMORE and EDWARD L. KORN

TECHNICAL REPORT NO. 35

MARCH 1980

PREPARED UNDER THE AUSPICES OF

SIAM INSTITUTE FOR MATHEMATICS AND SOCIETY

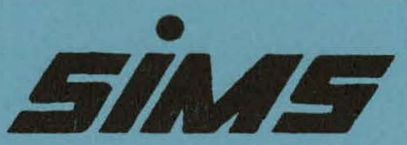

DEPARTMENT OF STATISTICS

STANFORD UNIVERSITY

STANFORD, CALIFORNIA

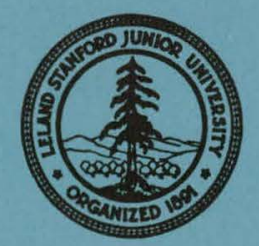

Prepared For

THE U.S. DEPARTMENT OF ENERGY

UNDER CONTRACT NO. DE-AS-02-76EV02874 


\section{DISCLAIMER}

This report was prepared as an account of work sponsored by an agency of the United States Government. Neither the United States Government nor any agency Thereof, nor any of their employees, makes any warranty, express or implied, or assumes any legal liability or responsibility for the accuracy, completeness, or usefulness of any information, apparatus, product, or process disclosed, or represents that its use would not infringe privately owned rights. Reference herein to any specific commercial product, process, or service by trade name, trademark, manufacturer, or otherwise does not necessarily constitute or imply its endorsement, recommendation, or favoring by the United States Government or any agency thereof. The views and opinions of authors expressed herein do not necessarily state or reflect those of the United States Government or any agency thereof. 


\section{DISCLAIMER}

Portions of this document may be illegible in electronic image products. Images are produced from the best available original document. 
Alice S. Whittemore

Stanford University.

and

Edward L. Korn

University of California at Los Angeles

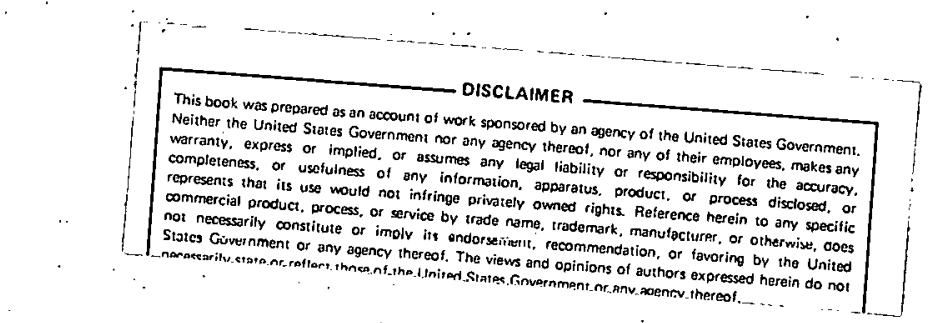

TECHNICAL REPORT NO. 35

MARCH 1980

STUDY ON STATISTICS AND ENVIRONMENTAL FACTORS IN HEALTH (SIMS)

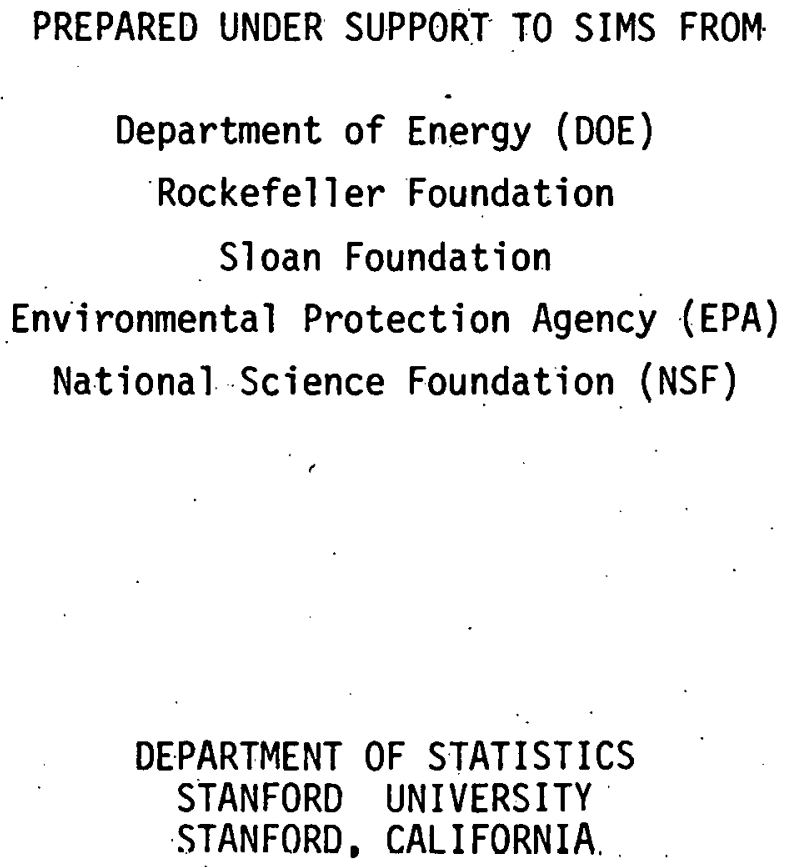


Asthma and Air Pollution in the Ios Angeles Area

\section{Summary}

Daily asthma attack diaries of sixteen panels of asthmatics residing in the Los. Angeles area were collected by the Environmental Protection Agency for 34 week periods during the years'1972-1975. These data are examined here for the relationship between daily attack occurrence and daily levels of photochemical oxidant, total suspended particulates, minimum temperature, relative humidity, and average wind speed. A separate multiple logistic regression is used for each panelist's attack data. Variables representing the presence or absence of attack on the preceding day, as well as day of week and time since the start of the study, are included in the regressions. The most significant predictor of attacks was the presence of an attack on the preceding day. On the average, the panelists tended to have increased attacks on days with high oxidant and particulate pollution, on cool days, and during the first two months of the study. Panelists' attack propensity also differed by day of week; in particular they had more attacks on Saturdays (the last day of the weekly reporting period) than on Sundays. Each panelist's regression coefficients are classified according to his age, sex, hay fever status and self-assessed attack precursors; this classification is used to examine subgroups among the panelists with high coefficients corresponding to the above factors. 


\section{Introduction.}

Asthma is a condition marked by recurrent attacks of paroxysmel dyspnea, with wheezing due to spasmodic contraction of the bronchi. Its onset and aggravation are ascribed to such factors as allergens, pollens, emotional stress, bronchopulmonary infection, air pollution and weather. Despite the prevalence and potentially fatal nature of this disease, until 1960 there had been few epidemiological studies attempting to clarify the roles of the above factors. Since then, concern with adverse health effects of the environment has stimulated a number of investigations, including studies in Los Angeles (1); Nashville (2,3); New York (4); Philadelphia (5); New Orleans (6); New Cumberland, West Virginia (7) and Leiden, the Netherlands (8). In 1970, in response to a mandate of Congress under the Clean Air Act, the Environmental Protection Agency (EPA) initiated a number of panel studies of the relationship between asthma and air pollution In the metropolitan areas of New York City (9) and Salt Lake City (10). These studies were part of a larger program entitled "The Community Health Environmental Surveillance System" (CHESS) whose objective was to evaluate the acute and chronic respiratory effects of air contaminants. Controversy over the technical correctness of the conclusions drawn from some of the early CHESS studies led, in 1976, to a Congressional investigative report (1I). This report qualifies and complements the CHESS findings by pointing out theoretical and bechnical Iimitations inherent in the statistical and epidemiological methodology. 
The purpose of the present paper is to report the results of an analysis of data collected by EPA-CHESS during the years 1972-1975 concerning sixteen panels of asthmatics residing in the Los Angeles area. Some of the early data, collected during 1972-1973 for five of the sixteen panels, have also been discussed elsewhere (12). Here we analyze the data using new statistical methods that avoid many of the biases and problems cited in (11). 


\section{Methods \\ 2.I The Panels}

Data from panels in the communities of Santa Monica, Anaheim and Glendora were collected during the 34 week periods from May $7^{\text {th }}$ to December $30^{\text {th }}$ in each of the three years 1972, 1973 and 1974, and in Thousand Oaks, Garden Grove and Covina during the 34 week periods from October $20^{\text {th }}$ to June $16^{\text {th }}$ in the years 1972-73, 1973-74, 1974-75.

-Panelists were located by consulting local physicians. An individual was selected to participate in a panel if he or she experienced at least one attack in the year before the study, gave a history of wheezing and dyspnea with each attack, lived within two miles of the community's air monitoring station, and coitsented to participate in the study. Questionable asthma diagnoses were verified by a physician. Participants were informed only that the roles of environmental factors in asthma were to be investigated. The panels were not expected to be representative of the general asthmatic population.

Subjects selected to participate in the study were asked for information on demographic variables, smoking habits, occupational exposures, and other factors apparently related to their attacks. The age and sex distribution of those panelists included in our anaiysis is shown for each of the panels in Table 1. Asthmatics who participated in panels for two or three years are treated as two or three individuals in the analysis. Approximately half of the individuals nominally in the panels could not be included in the analysis for reasons discussed in Section 4.?. 


\subsection{Attack Reporting}

Each panelist received a diary by mail each week. He was asked to record attacks when and where they occurred, to specify whether or not medication was taken, and to return the diary at the end of the week. Each diary covered the Sunday through Saturday period, and each day of reporting began at midnight. Nonresponses and diaries requiring clarification were investigated by telephone. Diaries received more than 12 days after the Saturday covered by the diary were not included in the data processing. Days when the individual was out of town were omitted from the analysis. Because of apparent overreporting of attacks at the start of a study, the first two weeks of each study period were also excluded from the analysis.

\subsection{Pollution and Weather Monitoring}

An air monitoring station was located in each community approximately six feet above ground level, and within a short distance of an elementary school. Twenty-four hour average concentrations of total suspended particulates (TSP), respirable suspended particulates (RSP), suspended sulfates $\left(\mathrm{SO}_{\mathrm{X}}\right)$, suspended nitrates $\left(\mathrm{NO}_{\mathrm{X}}\right)$, sulfur dioxide $\left(\mathrm{SO}_{2}\right)$, nitrogen dioxide $\left(\mathrm{NO}_{2}\right)$, and photochemical oxident $(\mathrm{Ox})$ were collected by analytic techniques described elsewhere $(11,13)$. Ihe twenty-four hour measurement periods began between IOAM and noon depending upon the community; air pollution measurements thus represent twenty-four hours of exposure prior to the (approximate) midpoint of each day of observation. Daily minimum and maximum temperatures, twenty-four hour average relative humidity and average wind speed and direction were obtained for Glendora and 
Covina at Ontario airport, for Garden Grove and Anaheim at Iong Beach airport, for Santa Monica at Los Angeles airport and for Thousand Oaks at Burbank airport. The twenty-four hour observation period for the weather variables extended from midnight to midnight.

Several of the panels had an appreciable amount of missing and/or unreliable data for the pollutants $\mathrm{NO}_{2}, \mathrm{SO}_{2}$ and $\mathrm{Ox}$. Inclusion of these pollutants in the multiple regressions would necessitate the deletion of all person-days when any one of the pollutant measurements was missing. Consequently CHESS measurements for these pollutants were not used in the analysis.

Because of the importance of oxidant as a potential health problem in (daily maximum hourly average in ppm)

the Ios Angeles area, oxidant levels / taken by county air pollution control districts (APCD's) were used in place of the CHESS measurements. Oxidant measurements obtained by the Orange County APCD in Anaheim were used for Anaheim and Garden Grove; Los Angeles County measurements in Azuza were used for Glendora and Covina, and Los Angeles County measurements in West Los Angeles were used for Santa Monica. No alternative oxidant measurements for Thousand Oaks were available until 1974, when ozone levels were measured by the Ventura County APCD at the CHESS station. Thus only the Thousand Oaks 1974-75 panel is included in this analysis. The locations of the CHESS, Los Angeles County and Orange County stations are shown in Figure 1. Details of the sampling methods used for ox and ozone can be found in (14). The contaminants TSP, RSP, NOX and SOX were highly correlated in many of the panels, so that regressions involving two. or more of these pollutants produced panel coefficients that fluctuated 
widely from panel to panel. Therefore TSP was used as a surrogate for this group of pollutants. TSP was chosen because it is regarded as , having the most reliable measurements (1l, p. 37). It is important that the role of TSP as an index for a complex mixture of pollutants be remembered when interpreting the results.

Thus, the pollution and weather variables used in the regressions are. 0x, TSP, minimum temperature, relative humidity and average wind speed. Median levels and average correlation coefficlents for these variables are shown in Tables 2 and 3 .

\subsection{Statistical Analysis}

The most common approach to the analysis of panel study data, namely regression of the daily panel attack rate* against levels of air pollution and weather, is plagued by'a number of difficulties (11,12, ] 5-17). Consequently we use a new method that avoids many of these problems by analyzing each individual's responses separately. The method, which is based upon a multiple logistic model for each individual's attack probability, has been described in detail elsewhere (17). We shall summarize here its essential features.

The probability $p(t)$ that a particular asthmatic has one or more attacks during day $t$ of the study is allowed to depend upon that day's levels of the aerometric and meterological variables, as well as upon the day of the week, the time since start of the study, and the presence or absence of an attack on the preceding day. Specifically, we assume

* The panel attack rate on any day is the number of panelists reporting an attack on that day divided by the number of panelists reporting on that day. 
that

$$
\text { logit } p(t)=a_{0}+a_{1} z_{t-1}+\underset{\sim}{b} x_{t}
$$

where logit $p(t)$ denotes the natural logarithm of the ratio $p(t) /[1-p(t)]$; $z_{t-1}$ is an indicator which assumes the value one if the asthmatic has an attack on day $t-1$ and zero otherwise; ${\underset{\sim}{t}}_{t}=\left(x_{t}^{(1)}, \ldots, x_{t}^{(p)}\right)$ is a vector representing known levels on day $t$ of the environmental covariates; $a_{0}, a_{1}$ and $\underset{\sim}{b}=\left(b_{1}, \ldots, b_{p}\right)$ are unknown parameters; and $\underset{\sim}{b} \underset{\sim t}{x_{t}}=b_{1} x_{t}^{(1)}+\cdots+b_{p} x_{t}^{(p)}$ is the inner product of the vectors $\underset{\sim}{b}$ and $\mathrm{x}_{\mathrm{t}}$. This model was motivated by a more detailed theory for the role of pollutants and other environmental factors in the aggravation of asthma (18). A noteworthy feature of the formulation is that attacks occurring on successive days are independent events only if $a_{1}=0$.

The parameters in the model, which are allowed to vary from person to person, were estimated for each individual by maximizing the likelihood of his data. An advantage of this separate estimation is that subgroups of the study population which are particularly susceptible to any one of the environmental factors can be detected via their high regression coefficients for that factor.

In order to obtain summary estimates of the effects of the environmentol covariates, the maximum likelihood estimates of the coefficients $b_{1}, \ldots, b_{p}$ were combined over the individuals in each panel, each person's contribution being weighted according to the amount of data that he contributed. Thus for example, an estimated panel coefficient corresponding to relative humidity is a weighted average of such coefficients, one for each of the panelists. The weights are inversely proportional to the estimated variances 
of the individual coefficient estimates, and they sum to one. The variance of a panelist's coefficient estimate is assumed to be the sum of a component $\sigma^{2}$ reflecting the variability of his data, plus a component $\tau^{2}$ reflecting interpanelist variability among the true coefficients. The reader is referred to (17) for details about estimating the regression coefficients and their variances, and about the assumptions underlying the procedure. For testing the hypothesis that each panelist's true coefficient corresponding to a covariate such as relative humidity is zero; i.e., that humidity has no effect on the asthma of any of the panelists, the interpanelist variance $\tau^{2}$ is taken to be zero. Setting $\tau^{2}$ equal to zero is equivalent to assuming that relative humidity has the same effect on, all of the asthmatics. Thus a panel coefficient that is obtained using weights with $\tau^{2}$ set equal to zero will be called a fixed effects coefficient. If $\tau^{2}$ is estimated from the data and included in the weights, the resulting panel coefficient is called a random-effects coefficient, because the true individual coefficients are assumed to vary from person to person.

In addition to the indicator for previous attack occurrence and the pollution and weather variables listed in Section 2.3 , the regressions included covariates for time since start of study and for day of week.

The covariate representing time since start of study was chosen to be an indicator assuming the value one during the first 60 days of observation, and zero elsewhere. This covariate was included to adjust 
for an increase in attacks during the first two months which was unaccompanied by a similar change in pollutants or weather. This increase, noted particularly in the panels observed from April to December, may reflect a seasonal effect due to unmeasured variables (e.g. allergens).

Day of the week was represented by six indicators for the days Monday through Saturday, with all six indicators assuming the value zero on Sunday. These covariates were included to adjust for the possibility of a systematic weekly pattern of asthma propensity, such as increased attacks on Mondays or weekends.

In summary, for the 1973-1974 and 1974-1975 panels; each subject's daily attack data were regressed via a multiple logistic regression function against the presence or absence of attack on the preceding day, daily levels of $0 x$, TSP, minimum temperature, relative humidity, and average wind speed, as well as against variables representing time since start of study and day of week. Regressions for asthmatics in the 19721973 panels included all of the above variables except average wind speed, which was not measured.

Days with missing attack data, either on the day itself or on the preceding day, as well as days with missing pollutant data, were not included in the regressions. Except for one data point which was interpolated, there were no missing weather data. 


\section{Results}

\subsection{Summary Estimates of Regression Coefficients}

In order to determine which factors were, on the average, associated with asthma in each panel, fixed effects panel coefficients were obtained for each of the variables listed at the end of Section 2.4. The variable with the largest effect on the panelists' daily attack probabilities was the presence or absence of attack on the preceding day. Indeed, individual estimates of the corresponding coefficient were nonzero at a level of significance less than .05 for virtually all of the. 443 panelists included in the analysis. This indicates autocorrelation between attacks on successive days that cannot be explained by autocorrelation in the daily weather and aerometric variables.

On the other hand, none of the sixteen panel coefficients corresponding to wind speed was significantly different from zero, nor was the corresponding fixed effects coefficient obtained by averaging the individual coefficients over the 443 panelists in all studies. Consequently wind speed was dropped from the regressions in order to obtain more precise estimates of the remaining coefficients.

Fixed effects panel coefficients corresponding to Ox, TSP, minimum temperature, relative humidity, time since start of study and Saturday are shown in Table 4. Although indicators for Monday through Saturday were included in the regressions, only the panel coefficient corresponding to Saturday is displayed in the table. This coefficient is an average of individual coefficients, each of which represents the difference in logit of attack probability between Saturday and Sunday, the last and first days of the diary reporting period. 
It is evident that on the average, the panelists tended to have more attacks initially than later in the study period, and more attacks on Saturdays than on Sundays. "It is not possible to determine the extent to which these effects are due to systematic temporal patterns in asthma episodes, or to biases in reporting.

The summary regression coefficients for $O x$, TSP, temperature, and humidity shown in Table 4 represent the average increase in logit of attack probability per unit increase in these variables. The entries in columns $4-6$ must be multiplied by $10^{-3}$. The panel coefficients for $O x$ and ISP indicate a consistent, small positive effect of these pollutants. The interpanel variability of the coefficients for temperature and humidity however, suggests that the effects of these factors vary from person to person.

These findings are consistent with the estimates of interpanelist variability among the coefficients, shown in Table 5. The significantly positive estimate of $\tau^{2}$ for temperature indicates that the standard errors of the individual coefficient estimates cannot account for their great variability among the panelists. This is also true of the coefficient estimates corresponding to humidity and time since start of study. By contrast, the coefficient estimates corresponding to TSP do not vary appreciably among the panelists relative to their estimated standard errors.

The first row of Table 5 contains fixed effects coefficient estimates averaged over the 443 panelists in all sixteen studies. The analagous random effects coefficient estimates, obtained using weights that include the estimated variance component $\hat{\tau}^{2}$, are shown in row 3 of the table. Since the estimate of $\tau^{2}$ for TSP is zero, the fixed effects and random effects coefficient estimates for this variable coincide. 
Table 5 shows that on the average, the asthmatics observed in the Los Angeles area during the years $1972-1975$ have significantly increased attacks on days with high levels of $O x$ and TSP, and on days with cool temperatures. It is also noteworthy that the presence of attack on the preceding day, day of week and day of study were highly significant predictors of an attack. This suggests that the likelihood is poor of detecting small pollutant effects and interactions among pollutants and weather variables by such panel studies without altering the study design.

The relative importance of the above factors in predicting asthma can be seen by estimating the increase in attack probability corresponding to specified changes in each factor. Such an increase depends upon the baseline attack probability without the increase, the amount of change in the factor, and the regression coefficient corresponding to the factor. The increases shown in Table 6 were calculated using the summary fixed effect coefficients of Table 5. Thus, for example, a panelist with an attack probability of .10 following an attack-free day would, on average (other things equal) have an attack probability of $.10+.31=.41$ on the day after an attack day. If his attack probability were .10 on a given day, an increase in oxidant level of $0.2 \mathrm{ppm}$ would raise it to .13 . The crude comparisons of Table 6 show that the effect of an attack on the preceding day dominates that of the remaining covariates.

The magnitude of the pollution effect can also be estimated from the relative risk (i.e. odds ratio) of attack corresponding to a specified pollutant increase. According to the multiple logistic model, this ratio depends only on the amount of the increase and the regression coefficient for the pollutant. The relative risks shown in Figure 2 were calculated 
using the summary fixed effects coefficients for oxidants and particulates displayed in Table 5. Thus they estimate the increased risk borne by a hypothetical asthmatic whose regression coefficients are the overall average values for all panelists in the study.

\subsection{Coefficients Classified According to Demographic Characteristics.}

For the purpose of detecting susceptible subgroups of the asthmatic population, the individual regression coefficients corresponding to each of the covariates shown in Tables 4 and 5 were classified according to sex, age (under or over age 16), and the reported presence or absence of hay fever, of increased attacks during cold weather, and of increased attacks during periods of emotional stress. There were too few non-whites and too few smokers to justify stratification by race or smoking status. For each covariate, a random effects coefficient and its variance were estimated for each of the 32 cells obtained by cross-classifying all 443 panelists according to the above five dichotomous characteristics. For each covariate a 5-way analysis of variance was performed, using the diagonal variance-covariance matrix with entries equal to the 32 estimated variances. A model with no interactions among the characteristi.cs was assumed.

It was found that males were affected significantly more by dry weather than were females. Panelists who reported increased attacks in cold weather were affected significantly less by oxidant than those who did not. As expected, these panelists were more affected by cool temperatures, but the difference was not significant. Adults were significantly less likely to report increased asthma early in the study period than were juveniles. There were no significant differences in response to particulate pollutants. This is 
consistent with the small interpanelist variability in TSP coefficients discussed in Section 3.1.

\subsection{Examination of Model Fit.}

The analysis described in the preceding sections involves several assumptions whose validity might, in principle, be tested. These include the linear dependence of the logit of attack probability on the environmental factors included in the regressions, the absence of delayed effects and of interactions among the factors, as well as the assumption that attacks depend only on the asthma events of the preceding day. One would also like to know whether the omission of such factors as allergens, daily emotional stress, other pollutants, respiratory infections and medication use has led to inadequate model fit. Unfortunately, the statistical theory for testing such assumptions within the framework of the multiple logistic model is not well developed. In this section we present three visual checks of model fit. Each involves the examination of residuals aggregated over many person-days.

A residual for a given person-day is defined to be the difference between the observed and the expected number of attacks for that person-day. Here the observed number is either 0 or 1 , and the expected number is the estimated attack probability for the person-day. If we regard the estimated attack probabilities as completely specified, then according to the model thc residuals for a given asthmatic on different days are uncorrelated. The sum of such residuals taken over several asthmatics on a particular day is approximately a normal variate, and sums corresponding to different days are uncorrelated. Consequently if the model 
is valid, the sum $O-E$ of residuals taken over all person-days in a specified category is approximately normally distributed about a mean of zero. The approximate standard error is $S E=[\Sigma \hat{p}(1-\hat{p})]^{l / 2}$, the sum being taken over all person-days for which the estimated attack probability $\hat{p}$ lies in the category. Thus the standardized residual sum $(\mathrm{O}-\mathrm{E}) / \mathrm{SE}$ is distributed approximately as a standard normal variate. An alternative measure reflecting the magnitude of the residuals is "residualo per person-day" (n-di)/N, where $N$ is the number of person-days in the category.

We first examined the relationship between residuals and attack risk. Accordingly, residuals were aggregated according to decile of estimated attack probability. The observed and expected number's of attacks among all 443 asthmatics are classified according to decile of attack risk in columns 3 and 4 of Table 7 . The residuals per personday show in column 6 of the table are small, and the standardized residual sums in column. 5 indicate no consistent departures from the model aceording lo this criterion. Similarly, the residuals aggreguted according to. declle of oxidant level in Table 8 show no extreme or systematic departure from the model.

As a third check, residuals were plotted against time in order to look for systematic seasonal or other temporal deviations from the model assumptions. Standardized residual sums aggrcgated by month are shuwn in Figure 3 . The Figure indicates significant departures from the model: an excess of observed attacks in April and September, and a deficit of observed attacks in December and January. The evident trend in these residuals suggests the omission of a seasonal predictor for asthma, such as pollen levels. 
4. Discussion

4.1 Comparison with Other Studies.

The relationship between increased frequency of asthmatic attacks and air pollution noted in the present studies is consistent with the findings of other investigations. Girsch et al (5) report a three-fold greater incidence of emergency visits to a children's hospital in Philadelphia during days of high air pollution. After controlling for temperature, Cohen et al (7) report a positive association between air pollution and attacks among a panel of asthmatics in New Cumberland, West Virginia, the site of a coal-fuel power plant. Neither of these studies could incriminate a specific pollutant. In a group of asthmatics followed in Pasadena, California, a significantly greater number of attacks occurred on days when the photochemical oxidant levels were high enough to cause eye irritation, and when pollutants caused plant damage (I). Comparison of attack rates among asthmatic panels in different residential areas of Nashville, Tennessee yielded a positive association between attacks among adults and sulfur dioxide levels in the area $(2,3)$.

Although the overall effect of low temperatures in the present study is significantly positive, it varies greatly from person to person. Increased attacks of asthma during periods of relatively cold weather have been reported in New orleans (6), New Cumberland, West Virginia (7), Leiden, the Netherlands (8), and the Salt Lake Basin (10). By contrast, the frequency of emergency visits to a chlldren's hospital in Fiiladelphia wes only weakly correlated with cool temperatures (5). Comparison of these results is difficult because of the differences in geography, wind, humidity and temperature extremes among the rarious cities. 
The effect of humidity in the present study is equivocal, as evidenced by the significant interpersonal variation shown in Table 5 . The suggestion in that table of an overall excess of attacks on days with low humidity is supported by a similar finding in New Orleans (6). This contrasts with the negative results of a controlled clinical study to determine the effect of changes in humidity on the pulmonary function of asthmatic children (19). The excess of attacks during the spring and fall. months discussed in the preceding section and shown in Figure 3 has been reported in other investigations. Greenburg et al (4) found that in the fail months in New York City there was a sharp rise in the number of hospital visits for treatment for asthma. A similar increase was noted in Filadelphia by Girsch et al (5). The latter authors also reported a peak in hospital. visits occurring during the month of May. It is not clear to what extent these increases are due to a common mechanism, such as seasonal changes in pollen counts.

\subsection{Implications for the Design of Future Studies.}

The present analysis avoids two problems that weaken the conclusions of previous panel studies: the dependence between attacks on successive days, and the possible bias due to "drop-ins" and "drop-outs" of panelists with high or lnw attack frequencies. Thio bias is avoided because each person's days of' morbidity are compared only with his own days of good health.

Nevertheless there remain limitations inherent in the dcoign of such panel studies that cannot be eliminated by the statistical methodology. Although the panelists in the present studies were confirmed asthmatics, 
attack ascertainment was based upon the subjective appraisal of the panelist, with no clinical validation. Therefore the observed day of week and day of study effects might be due to biases in reporting. Moreover there is no clear-cut way to combine medication use with reported attack occurrence. Both of these problems would be alleviated by the use of automated, timed medication dispensers in place of daily diaries; with daily asthma response represented by amount of medication taken.

Perhaps the most serious limitation of all epidemiological studies of the health effects of air pollution is the absence of information on individual pollutant exposure. Future investigations shouid collect data on air conditioning, fuel heating, presence of cigarette smoke, as well as fraction of time spent at home and at work or school. Using these data, a separate estimate of daily exposure could be obtained for each subject on study. These estimates could easily be incorporated into the present analysis, since each subject's data is analyzed individually. In addition, data concerning respiratory infections, emotional factors and allergens should be included in the individual regressions.

Use of the present statistical approach has implications for the choice of panel size and study period length in future studies. Approximately half of the panelists nominally included in the present panels could not be included in the analysis. Some never reported; some had very few attacks; others had an attack virtually every day. Moreover when the day of study variable was omitted and the day of week variables were modified in order to include an additional 325 of these panelists, the variances of their regression coefficients were so large that they had a 
negligible effect on the overall conclusions. This suggests that more careful screening and follow-up of panelists and longer study periods would be more cost-effective.

Monte Carlo simulations would be helpful in determining the minimal study length necessary to detect a given environmental effect among a specified number of panelists.

Acknowledgements:

The authors would like to thank Glen Cass, Wlillam ivelson and Ronald Wyzga for discussions and materials that made this work possible. This research has been supported by grants to the SIAM Institute for Mathematics and Society from the National Science Foundation, the Department of Energy, the Environmental Protection Agency, the Rockefeller Foundation and the Sloan Foundation, and by grants numbered CA $23214-01$ and CA 16042 from the National Cancer Institute, DHEW. 


\section{$\underline{\text { References }}$}

(I) Schoettlin, CE and Landaw E. Air pollution and asthmatic attacks in the Los Angeles area. Pub. Health Reports 76: 545-549, 1961.

(2) Zeidberg, LD, Prindle, RA and Landau, E: The Nashville air pollution study 1. Sulfur dioxide and bronchial asthma. Am. Rev. Resp. Dis. 84: $489-503,1961$.

(3) Landau,E. The Nashville Air Pollution Study. Sulfur dioxide and bronchial asthma- a multivariate analysis. Int. J. Env. Studies 2: $41-45,1971$.

(4) Greenburg: L, Field F, Reed $J$ and Erhardt C. Asthma and temperature change: An epidemic study of emergency clinic visits for asthma in three large New York hospitals. Arch. Env. Health 8: $642-647,1964$.

(5) Girsh, IS, Shubin, E, Dick, C and Schulaner, FA. A study on the epidemiology of asthma in children in Phildelphia. The relation of weather and air pollution to peak incidence of asthmatic attacks. J. Allergy 39: 347-357, 1967.

(6) Salvaggio, J, Hasselblad, V, Seabury, J and Heiderscheit, IT. New Orleans asthma II. Relationship of climatologic and seasonal factors to outbreaks. J. Allergy 45: 257-265, 1970.

(7) Cohen, AA, Bromberg, S, Buechley, RW, Heiderscheit, LT and Shy, CM: Asthma and air pollution from a coal-fueled power plant. Amer. J. Pub. Health 62: 1181-1188; 1972 .

(8) Tromp SW. Biometeorological analysis of the frequency and degree of asthma attacks in the Western part of the Netherlands, in Biometeorology Proc. of $2^{\text {nd }}$ Internat. Bioclimatological Conf. 1962, Oxford 1963 Pergamon Press, Inc. 477-492.

(9) Finklea, JF, Farmer, JH, Love, GJ, Calafiore, DC, Sovocool, GW. Aggravation of asthma by air pollutants: 1970-1971 New York Studies. In Health Consequences of Sulfur Oxides: A report from CHESS, 1970-1971 US EPA, Research Triangle Park, INC EPA-650/1-74-004 (1974). 5-71-5-84.

(10) Finklea, JF, Cailafiore, DC, Nelson, CJ, Riggan, WB, Hayes, CG. Aggravation of asthma by air pollutants: 1971 Salt Lake Basin Studies. In Health Consequences of Sulfur Oxides: A report from CHESS, 1970-1971. US EPA, Research Triangle Park, NC EPA-650/1-74-004 (1974). 2-71 - 2-91.

(II) United States Congressional Report. The Environmental Protection Agency's research program, with primary emphasis on CHESS: An investigative report. Prepared for the Committee on Science and Technology, United States House of Representatifes. US Gov. Printing Office (1976). 77-590. 
(12) Viren, JR, Roth,HD, Colucci, AV, Finkelstein, PD. Asthma in six Los Angeles communities: An analysis of findings based upon CHESS 1972-1973, Report for Southern California Edison, Rosenmead, CA (1978).

(13) Health Consequences of Sulfur Oxides: A report from CHESS, 1970-1971. US EPA, Research Triangle Park, NC. EPA-650/1-74-004 (1974).

(14) California Air Quality Data, Vols. 5-7. Cal. Air Resources Bd., Technical Services Div., Sacramento, CA, 1973-75.

(15) Roth, HD, Viren, iR, Cnlunni, AV. Evaluation of CHEEE: New York As thmè Data 1970-1971, Vol. I. EPRI EA- 50. Electric Power Res. Inst., Palo Alto, CA. (1977).

(16) Stebbings, JH, Hayes, CG: Panel studies of acute health effects of air pollution. Env. Res.11: 89-111; 1976.

(17) Korn, EL and Whittemore, AS. Methods for analyzing data from panel studies of acute health effects of air pollution. Biometrics 35: $795-802$, 1979.

(\$8) Whittemore, AS and Keller, JB. Asthme and air pollution: A quantitative theory. Proc. SIMS Conf. on Energy and Health, N.E. Breslow and A.S. Whittemore, eds. SIAM Publications, Philadelphia, PA, 1979.

(19) Fontana, VJ, Fost, $A$ and Rappaport, I. Effects of rapid change in humidity on pulmonary function studies in normal and asthmatic children in a controlled environment. J. Allergy 43: 16-19, 1.969 . 


\section{TABLE 1}

Age and Sex of Asthmatics in Sixteen Los Angeles Panels, 1972-1975

\begin{tabular}{|c|c|c|c|c|c|c|}
\hline \multirow{2}{*}{ Community } & \multirow[b]{2}{*}{ Year } & \multicolumn{2}{|c|}{ Male } & \multicolumn{2}{|c|}{ Female } & \multirow[b]{2}{*}{ Total } \\
\hline & & Juvenile $\mathrm{e}^{\mathrm{a}}$ & Adult & Juvenile $e^{a}$ & Adult & \\
\hline Santa Monica & $\begin{array}{l}1972 \\
1973 \\
1974\end{array}$ & $\begin{array}{r}6 \\
15 \\
7\end{array}$ & $\begin{array}{l}0 \\
0 \\
2\end{array}$ & $\begin{array}{l}3 \\
8 \\
4\end{array}$ & $\begin{array}{l}1 \\
5 \\
8\end{array}$ & $\begin{array}{l}10 \\
28 \\
21\end{array}$ \\
\hline Anaheim & $\begin{array}{l}1972 \\
1973 \\
1974\end{array}$ & $\begin{array}{l}10 \\
13 \\
11\end{array}$ & $\begin{array}{l}0 \\
4 \\
3\end{array}$ & $\begin{array}{l}4 \\
4 \\
2\end{array}$ & $\begin{array}{l}6 \\
3 \\
5\end{array}$ & $\begin{array}{l}20 \\
24 \\
21\end{array}$ \\
\hline Glendora & $\begin{array}{l}1972 \\
1973 \\
1974\end{array}$ & $\begin{array}{l}7 \\
9 \\
3\end{array}$ & $\begin{array}{l}6 \\
5 \\
6\end{array}$ & $\begin{array}{l}8 \\
9 \\
7\end{array}$ & $\begin{array}{r}7 \\
8 \\
10\end{array}$ & $\begin{array}{l}28 \\
31 \\
26\end{array}$ \\
\hline Thousand Oaks & $1974-75$ & 14 & 6 & 3 & 12 & 35 \\
\hline Garden Grove & $\begin{array}{l}1972-73 \\
1973-74 \\
1974-75\end{array}$ & $\begin{array}{r}14 \\
13 \\
8\end{array}$ & $\begin{array}{r}5 \\
6 \\
10\end{array}$ & $\begin{array}{l}6 \\
6 \\
7\end{array}$ & $\begin{array}{r}5 \\
11 \\
16\end{array}$ & $\begin{array}{l}30 \\
36 \\
41\end{array}$ \\
\hline Covina & $\begin{array}{l}1972-73 \\
1973-74 \\
1974-75\end{array}$ & $\begin{array}{l}11 \\
12 \\
12\end{array}$ & $\begin{array}{l}3 \\
3 \\
6\end{array}$ & $\begin{array}{l}8 \\
8 \\
7\end{array}$ & $\begin{array}{r}6 \\
5 \\
11\end{array}$ & $\begin{array}{l}28 \\
28 \\
36\end{array}$ \\
\hline Total & & 166 & 65 & 94 & 119 & 443 \\
\hline
\end{tabular}

${ }^{\text {a Aged } 16}$ years or less 
Median Levels of Pollution and Weather Variables in Los Angeles Communities during 32 Week Period ${ }^{\mathrm{a}}$, 1972-75

\begin{tabular}{|c|c|c|c|c|c|c|}
\hline Community & Year & $\begin{array}{l}\text { Ox } \\
\text { ppm }\end{array}$ & $\begin{array}{c}\mathrm{TSP} \\
\mu \mathrm{g} / \mathrm{m}^{3}\end{array}$ & $\begin{array}{c}\text { Minimum } \\
\text { temperature } \\
\text { Fo }\end{array}$ & $\underset{\%}{\text { Humidity }}$ & $\begin{array}{l}\text { Wind } \\
\text { speed } \\
\text { mi/hr }\end{array}$ \\
\hline Santa Monica & $\begin{array}{l}1972 \\
1973 \\
1974\end{array}$ & $\begin{array}{l}.05 \\
.07(1)^{b} \\
.06\end{array}$ & $\begin{array}{ll}68.4 & (3)^{b} \\
68.7 & (9) \\
73.8 & (39)\end{array}$ & $\begin{array}{l}59.0 \\
59.0 \\
61.0\end{array}$ & $\begin{array}{l}75.0 \\
77.0 \\
79.0\end{array}$ & $\begin{array}{l}- \\
6.9 \\
7.3\end{array}$ \\
\hline Anaheim & $\begin{array}{l}1972 \\
1973 \\
1974\end{array}$ & $\begin{array}{ll}.04 & (4) \\
.07 & \\
.07 & (1)\end{array}$ & $\begin{array}{ll}81.6 & (10) \\
84.8 & (5) \\
95.7 & (33)\end{array}$ & $\begin{array}{l}60.0 \\
58.0 \\
60.0\end{array}$ & $\begin{array}{l}67.0 \\
72.0 \\
66.5\end{array}$ & $\begin{array}{l}- \\
5.9 \\
5.0\end{array}$ \\
\hline Glendora & $\begin{array}{l}1972 \\
1973 \\
1974\end{array}$ & $\begin{array}{l}.12 \\
.15 \\
.14\end{array}$ & $\begin{aligned} 99.1 & (18) \\
121.4 & (1 .) \\
105.8 & (20)\end{aligned}$ & $\begin{array}{l}56.0 \\
56.0 \\
55.0\end{array}$ & $\begin{array}{l}66.0 \\
67.0 \\
67.5\end{array}$ & $\begin{array}{l}- \\
8.0 \\
8.1\end{array}$ \\
\hline Thousand Oaks & $1974-75$ & $.05(1)$ & 51.1 (12) & 43.0 & 67.0 & 5.5 \\
\hline Garden Grove & $\begin{array}{l}1972-73 \\
1973-74 \\
1974-75\end{array}$ & $\begin{array}{ll}.03 & (4) \\
.04 & \\
.04 & (2)\end{array}$ & $\begin{array}{ll}73.3 & (8) \\
71.6(34) & (34.9 \\
75.9\end{array}$ & $\begin{array}{l}48.0 \\
49.0 \\
50.0\end{array}$ & $\begin{array}{l}66.5 \\
66.0 \\
71.0\end{array}$ & $\begin{array}{l}- \\
4.6 \\
7.2\end{array}$ \\
\hline Covina & $\begin{array}{l}1972-73 \\
1973-74 \\
1974-75\end{array}$ & $\begin{array}{l}.01 \\
.06 \\
.05\end{array}$ & $\begin{array}{ll}75.4 & (7) \\
90.4 \quad(81) \\
90.9(12)\end{array}$ & $\begin{array}{l}16.0 \\
47.0 \\
43.0\end{array}$ & $\begin{array}{l}67.0 \\
68.0 \\
74.0\end{array}$ & $\begin{array}{l}= \\
8.1 \\
8.1\end{array}$ \\
\hline
\end{tabular}

ata collected during the first two weeks of each 34 week study period were not analyzed

${ }^{b}$ In parentheses are number of days with missing data

${ }^{c}$ No wind measurements were collected for the 1972-73 studies 
TABLE 3

Product-Moment Correlation Coefficients ${ }^{a}$ of Pollution, and Weather Variables Averaged over 16 Los Angeles Panels ${ }^{b}, 1972-75$

$\begin{array}{lccccc} & 0 x & \text { TSP } & \begin{array}{l}\text { Minimum } \\ \text { Temperature }\end{array} & \begin{array}{l}\text { Relative } \\ \text { Humidity }\end{array} & \begin{array}{l}\text { Average } \\ \text { Wind Speed }\end{array} \\ \text { Ox } & 1 & & & \\ \text { TSP } & 0.37 & 1 & 1 & & \\ \begin{array}{l}\text { Minimum } \\ \text { Temperature }\end{array} & 0.41 & 0.06 & 0.19 & 1 & \\ \begin{array}{l}\text { Relative } \\ \text { Humidity }\end{array} & -0.08 & -0.11 & 0.22 & -0.12 & 1 \\ \begin{array}{l}\text { Average } \\ \text { Wind Speed }\end{array} & -0.03 & -0.21 & 0.21 & \end{array}$

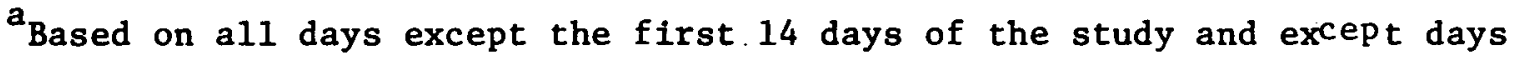
for which either of the two relevant measurements was missing.

${ }^{b}$ Correlations involving wind speed were averaged over those eleven panels with wind measurements. 
TABLE 4

Panel Coeficients Obtained ${ }^{a}$ From Subjects' Multiple Regressions ${ }^{b}$ For 16 Los Argeles Asthma Panels, 1972-1975

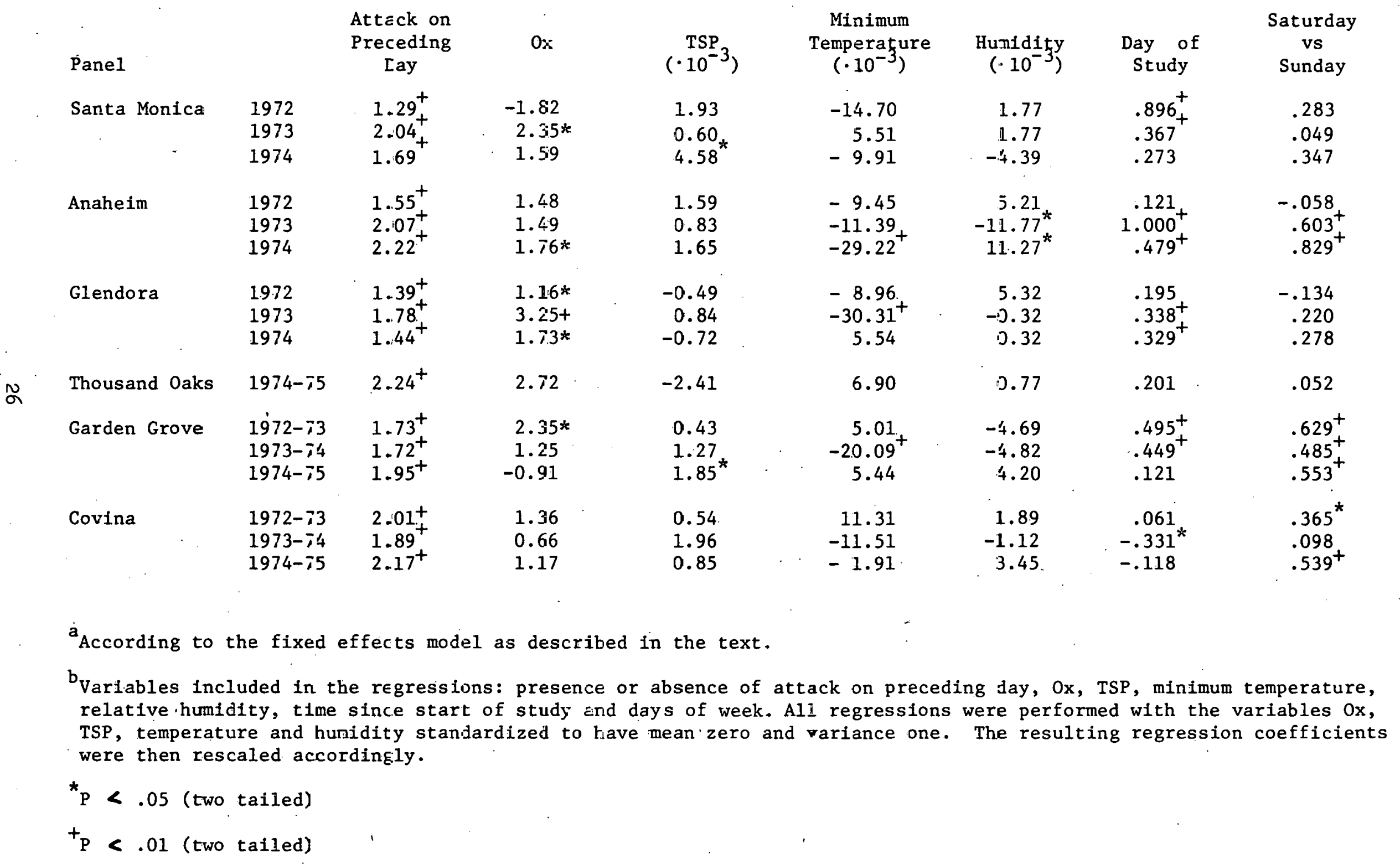




\section{TABLE 5}

Coefficients Obtained from Multiple Logistic Regressions of 443 Asthmatics in 16 Los Angeles Panels, 1972-1975

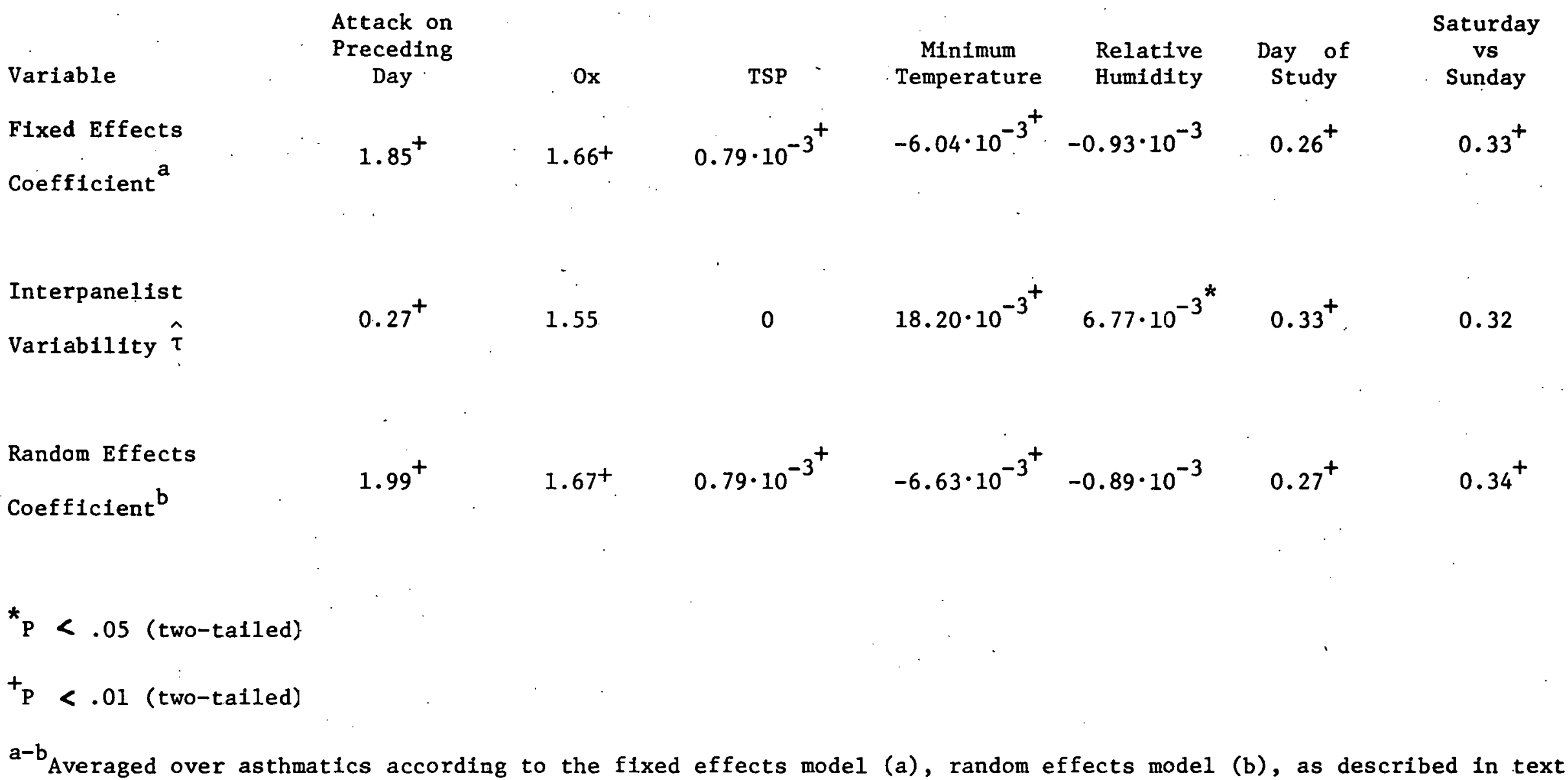


TABLE 6

Increase in Attack Probability Corresponding to Specified

Baseline Probabilities and Covariate Changes

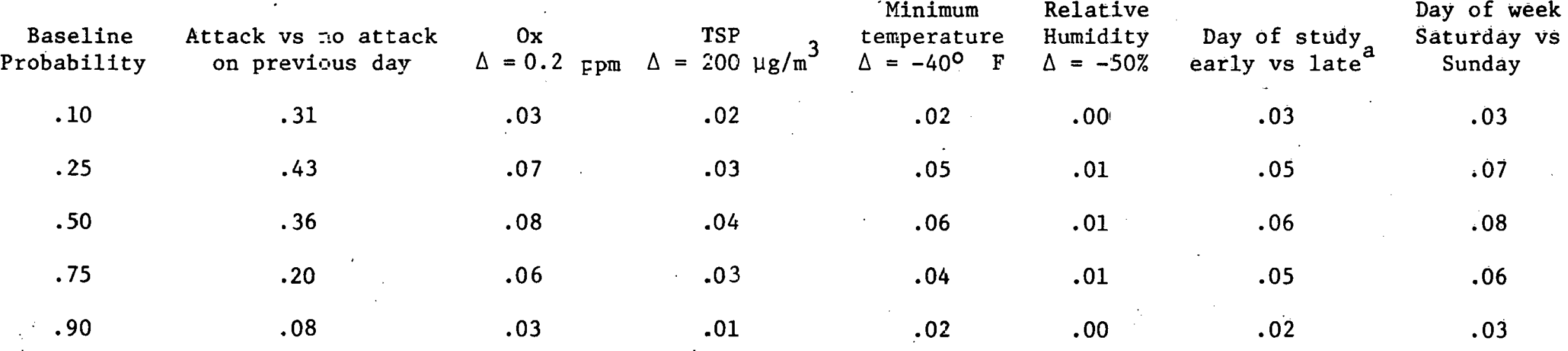

N

$a_{\text {The first }} 60$ dlays of the study are cllassfied as "early" days 
TABLE 7

Observed and Expected ${ }^{\text {a }}$ Numbers of Attacks Among 443. Asthmatics

in 16 Los Angeles Panels by Dectle of Attack Risk

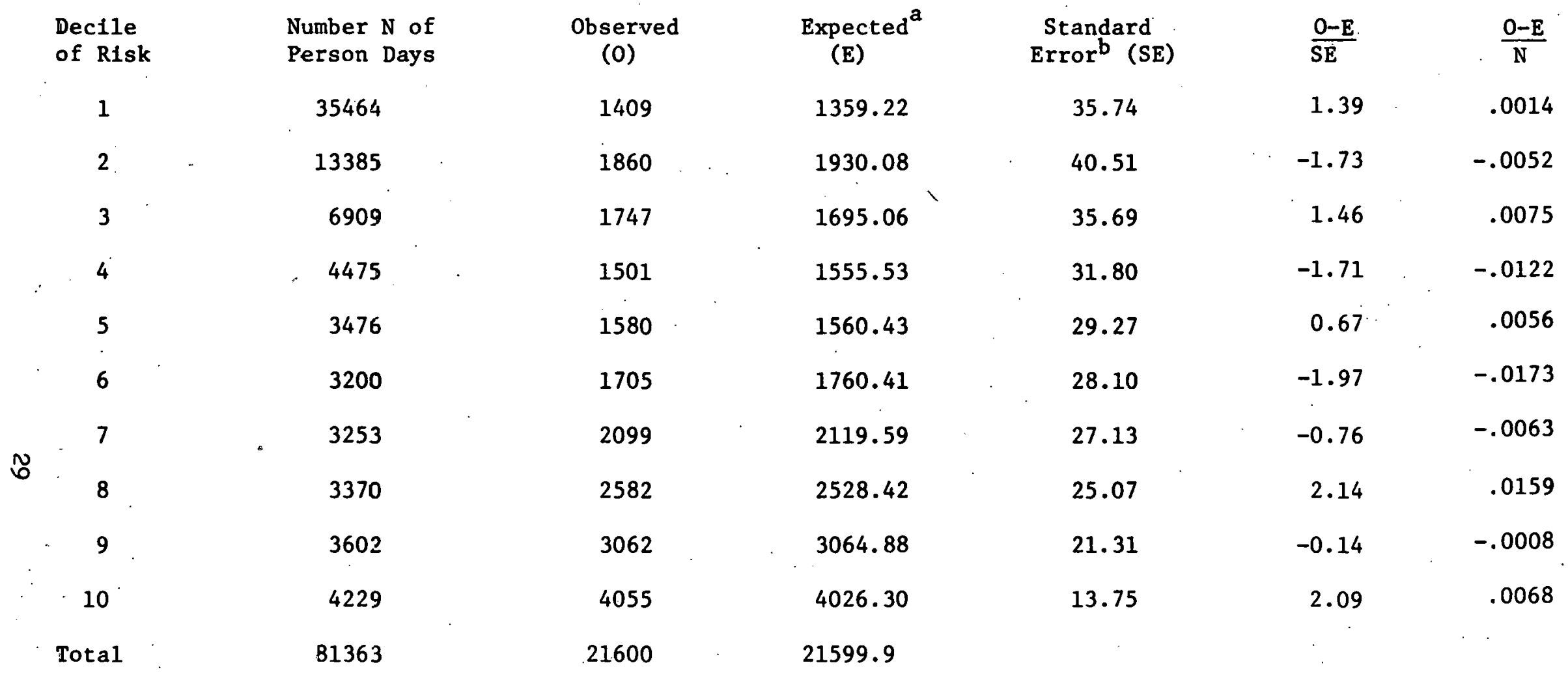

${ }^{3}$ The expected number of attacks in a decile is the sum of the estimated attack probabilities taken over all person-days for which the probability lies in the dectle.

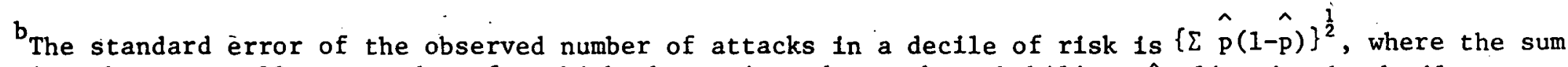
is taken over all person-days for which the estimated attack probability $\hat{p}$ lies in the decile. 
TABLE 8

Observed and Expected ${ }^{a}$ Numbers of Attacks Among 443 Asthmatics

in 16 Los Angeles Panels by Decile of Oxidant Level

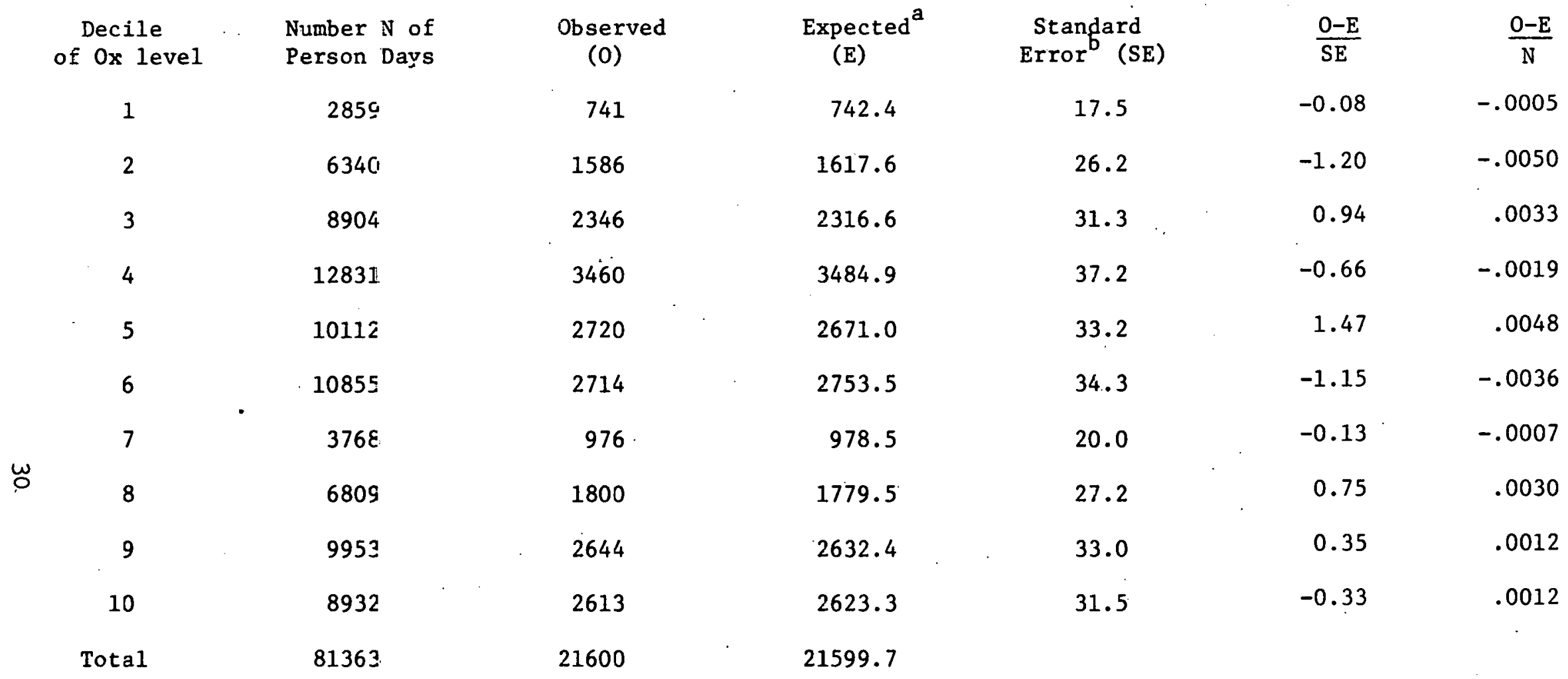

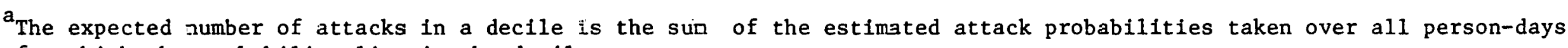
for which the probability lies in the dectle.

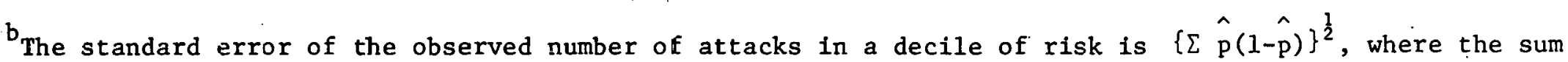
is taken over all perscn-days for which the estimated attack probability $\hat{p}$ lies in the decile. 


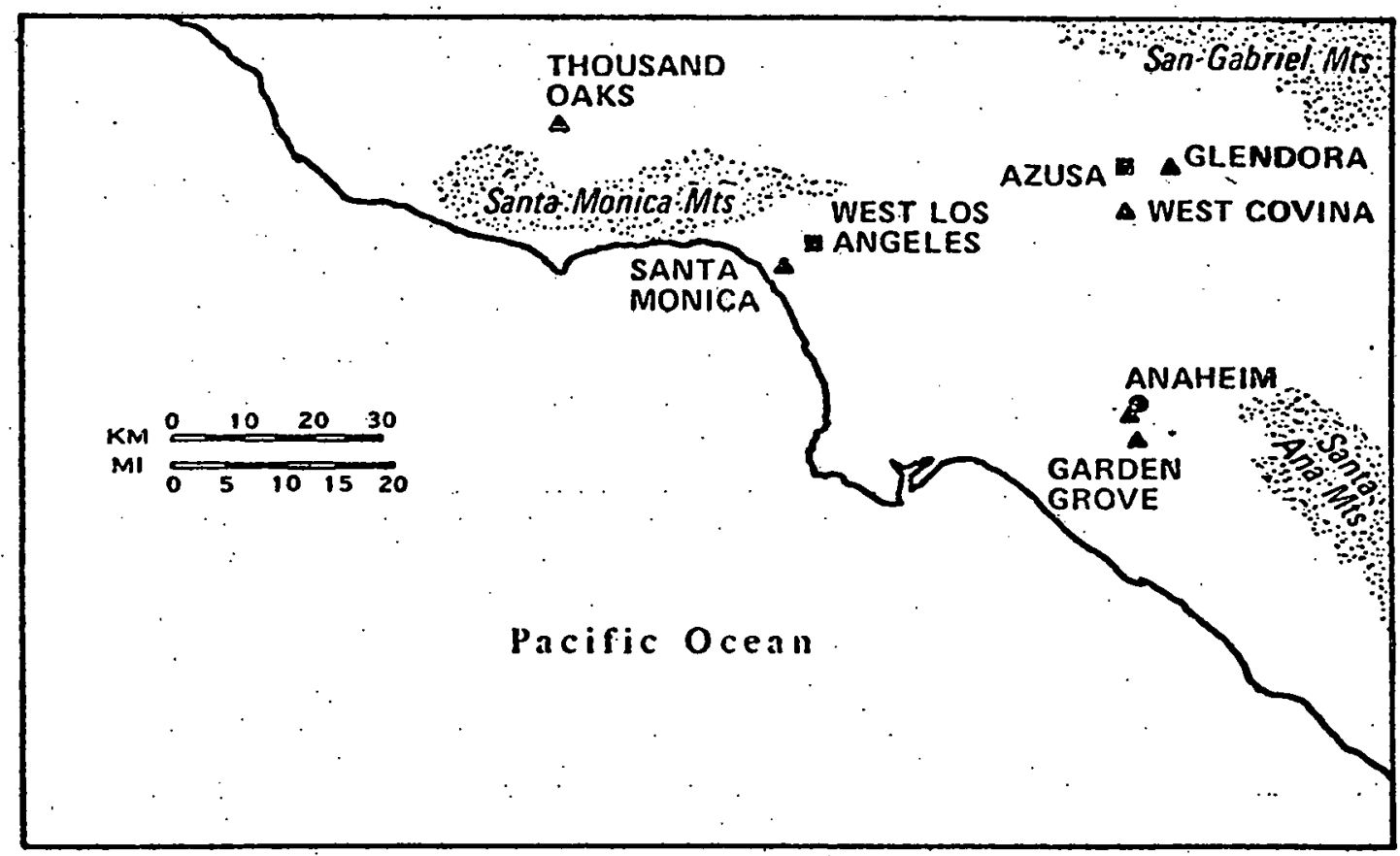

Figure 1.

Locations of the CHESS ( $\boldsymbol{A})$, Orange Country Air Pollution Control District (-) and Los Angeles County Air Pollution Control District (a) monitoring stations. 

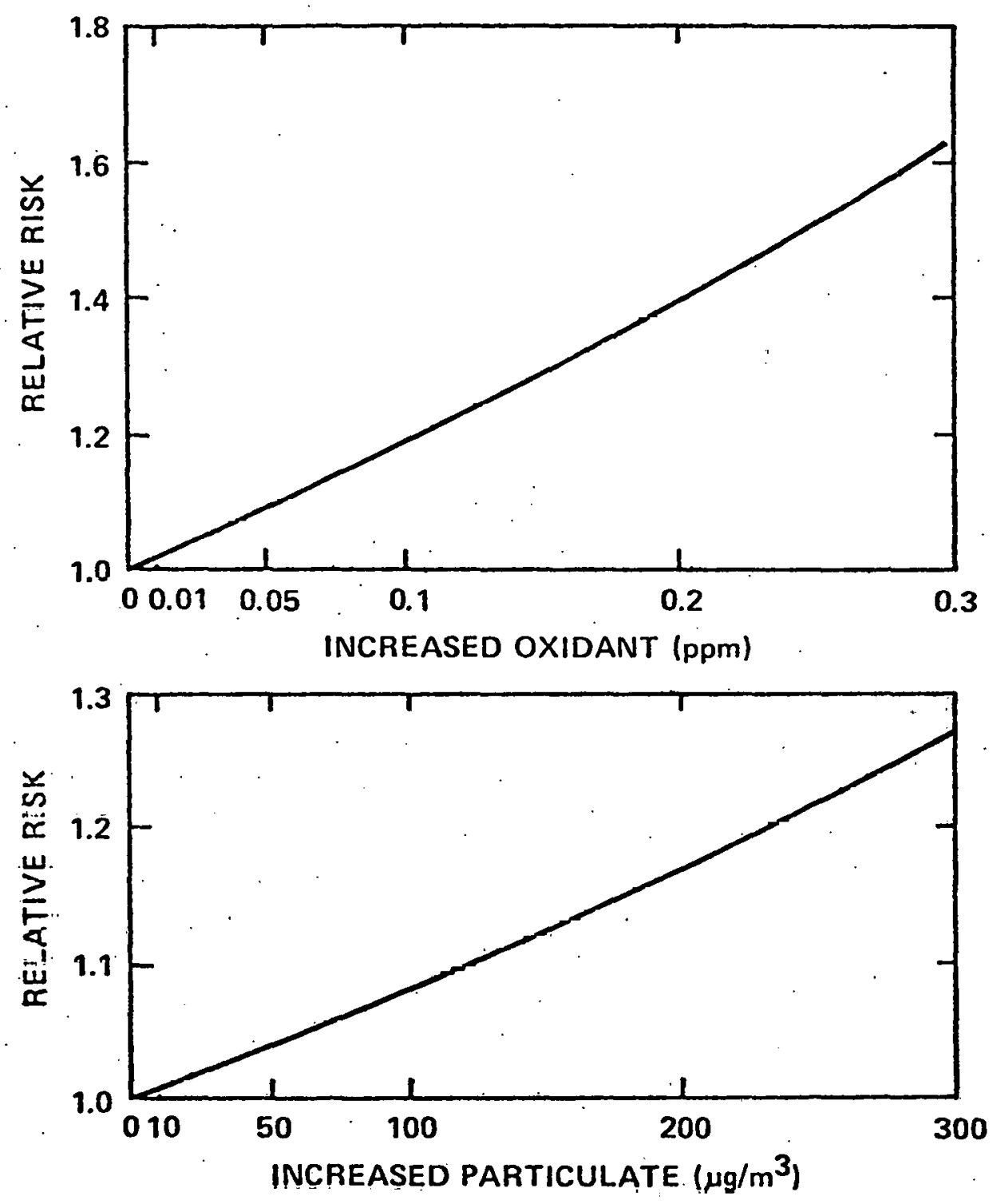

Figure 2.

Relative risk (i.e. odds ratio) of attack corresponding to specified increases in oxidant level (A) and particulates (B) with all other variables held fixed. The odds ratios were computed using the summary fixed effects coefficients 1.66 for oxidant and $0.79 \cdot 10^{-3}$ for particulates. 


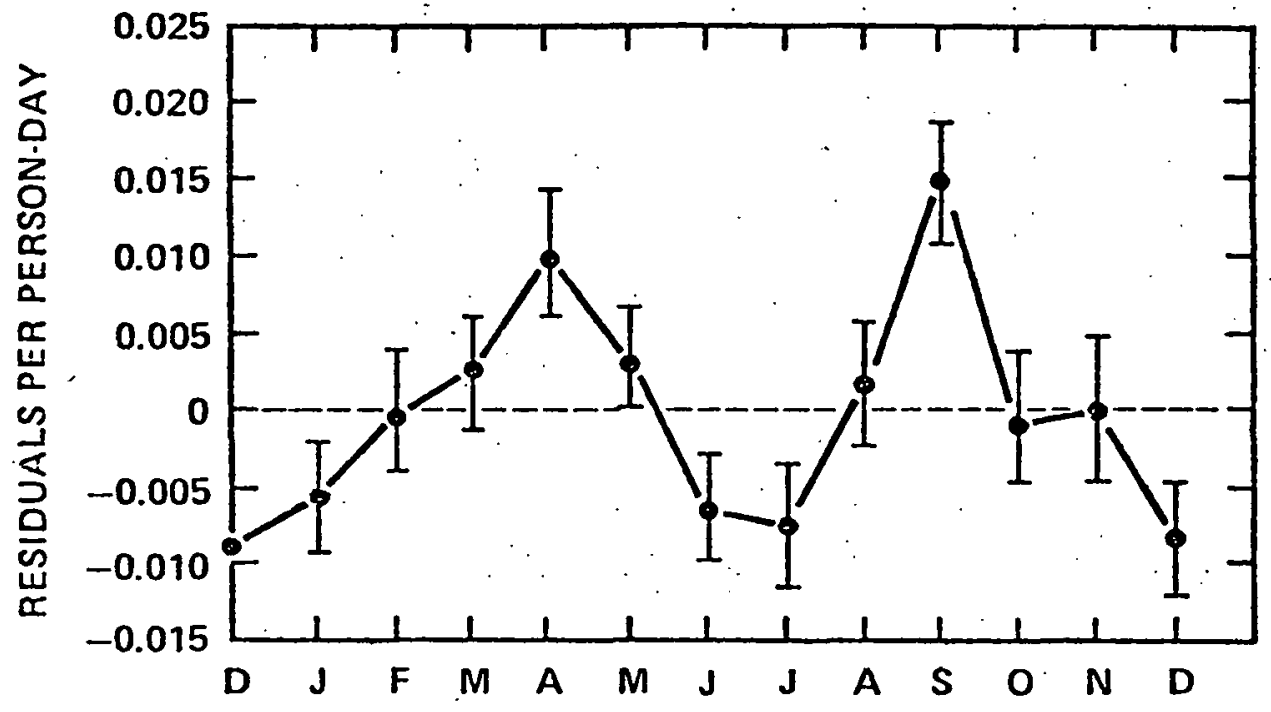

Figure 3.

Monthly differences between observed and expected numbers of attacks divided by the number of person-days of observation in the month. Vertical bars represent \pm one standard error. 